Síntese - Rev. de Filosofia v. 31 N. 100 (2004): 213-224

\title{
O REGISTRO FILOSÓFICO DO FILEBO E A DIALÉTICA
}

Sonia Maria Maciel PUC-R S*

Resumo: 0 objetivo deste artigo é mostrar que 0 entrelaçamento das questões filosóficas, usado por Platão no Filebo, tem a pretensão de sustentar e justificar um procedimento metodológico. Este método chamado por Platão de dialética é um procedimento sistemático que tem na diaíresis uma técnica a serviço de um desenvolvimento argumentativo. Nesse sentido é apresentado o desdobramento de alguns aspectos do modelo dialético explicitado no Filebo, como a estrutura Uno-Múltiplo e Limite-llimitado, os quais definem a sua especificidade em relação ao método herístico, criticado por Platão como impróprio para dar conta da multiplicidade indeterminada do real.

Palavras-chave: Platão, Filebo, método, dialética, diaíresis.

Abstract: This article aims to show that the entwinement of the philosophical questions, used by Plato in Philebus, intends to support and justify a methodological procedure. This method referred by Plato as dialectics is a systematical approach using diaíresis as a technique to support an argumentative development. In this sense, the development of some aspects of the dialectical model explicit in Philebus, namely the structure One-Many, Limited-unlimited,

\footnotetext{
* Atualmente trabalhando como professora convidada no Departamento de Filosofia Antiga da Universidade Toulouse-le Mirail, Toulouse, France.
} 
is presented. Plato opposed these methods to the heristic methods that, according to him, did not explain the indeterminate multiplicity of reality.

Key words: Plato, Philebus, methods, dialectics, diaíresis.

\section{1 - Considerações gerais sobre o Filebo}

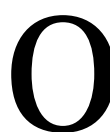

s herdeiros e os contemporâneos ${ }^{1}$ de Platão são quase todos unâ nimes em afirmar que o Filebo possui um complexo entrelaçamen to de questões filosóficas as quais tornam muito difícil a compreensão do tema que sustenta o diálogo. Nele a discussão socrática, que confronta a tese hedonista e a tese intelectualista, sofre inúmeras transformações por conta das longas digressões introduzidas abruptamente, as quais mais complicam e obscurecem 0 argumento do que 0 elucidam. Os impasses na leitura surgem da falta de explicitação e demonstração da parte de Platão ao introduzir as grandes questões filosóficas que vão aos limites de suas elaborações finais, na fundamentação dialético-metafísica dos problemas apresentados no texto. Apesar disso, o diálogo é a mais notável obra ética elaborada pelo fundador da Academia e é também onde os processos dialéticos, especialmente a diaíresis, são mais claramente desenvolvidos na articulação dos "aspectos metodológicos e metafísicos" 2 . Assim, a leitura do diálogo requer muita atenção e uma certa paciência, caso contrário o leitor perderá a riqueza do pensamento filosófico nele exposto, o qual oferece sempre novos horizontes no desvendamento de suas dificuldades.

Que fim, verdadeiramente, persegue Platão com as páginas do Filebo? Num primeiro momento, a questão parece evidente: trata-se "de indicar um estado e uma disposição da alma capaz de assegurar a todos os homens uma vida feliz (ton bion eudaímona 11d6)" ${ }^{3}$. Todavia, a vida feliz para todos os homens, questão de ordem prática, é apenas um dos níveis a ser abordado, pois, no nível teórico, a grande questão é a natureza do

\footnotetext{
1 J á DAmácıo e J Âmblico falam da complexidade que representa, para o entendimento do diálogo Filebo, o entrelaçamento de questões metafísicas que Platão não explicita, mas simplesmente pressupõe.

${ }^{2}$ M. MIGLIORI, 1998, p. 77. Isto porque o verdadeiro problema se encontra em como, a partir de uma visão direcionada às coisas do devir, se pode passar para uma realidade ontologicamente diversa.

${ }^{3}$ Para todas as referências ao texto do Filebo, utilizo a tradução de A. Dı̇̇s, ficando a tradução do francês para o vernáculo sob minha responsabilidade.
} 
Bem (agathòn 11b3), princípio ético, ontológico e cosmológico. A partir dessas modulações temáticas Platão examina inicialmente duas possibilidades de vida: uma em que o bem para o homem funda-se sobre o prazer, e outra em que o bem funda-se sobre a reflexão. Mas, ao mesmo tempo, é também analisado o problema do Bem em relação ao Uno e ao Múltiplo, aos princípios de Limite, Ilimitado, Mistura e Causa. Porém, todas essas articulações não terão um tratamento paralelo. De um total de 2369 linhas, Platão utiliza 1205 para um estudo detalhado do prazer e das ciências, ou seja, mais da metade do diálogo versa sobre questões de ordem prática. $\mathrm{Na}$ parte restante, são discutidos conceitos fundamentais, caracterizados hoje como teóricos, de natureza ética, ontológica, cosmológica e teológica. Desta sorte, é importante ter em conta a singularidade dessa construção e as implicações que dela resultam, no que concerne à interligação entre os resultados teóricos e práticos, ou, ainda, entre o que se poderia chamar "ética hedonista" e "ética intelectualista ".

Deve-se ainda acrescentar que, apesar de o texto mostrar-se um tanto enigmático em relação aos problemas metafísicos, ele apresenta um desdobramento coeso e coerente da relação método / problema. As razões que conduzem a essa afirmação são internas ao desenvolvimento do diálogo, pois, de fato, o encadeamento entre ética e ontologia, entre comportamento e fundamentação última, bem como o juízo sobre a vida feliz e o princípio que a rege e justifica, está em conformidade com os procedimentos da dialética. Com efeito, o itinerário tem início quando Sócrates sugere que se parta da unidade genérica de prazer e reflexão e, com a utilização do método de divisão (diaíresis 20c4), se atinja a indeterminada multiplicidade das coisas sujeitas à geração e à corrupção, ou as multiplas espécies em que se apresentam esses dois elementos em cada ser humano. Com isso, segundo ele, será possível identificar as características que assume cada um dos dois elementos e examinar se eles se identificam com o Bem. Portanto, no Filebo é apresentada uma estrutura capaz de dar conta da inteligibilidade do real e um método que permite apreender 0 inteligível. Este método é 0 dialético, e aos seus procedimentos de divisão chama-se diaíresis. Todas as distinções serão feitas, então, através desse método de investigação que "tem na diaíresis um instrumento a serviço de uma técnica" ${ }^{4}$ que se entrelaça ao processo argumentativo, pois as divisões são feitas sempre a partir de um julgamento ético dos elementos participantes 5 .

\footnotetext{
${ }^{4}$ PaVIani, 2001, p. 131.

${ }^{5}$ Platão, sempre que fala da dialética, se refere àqueles que a praticam. Portanto, não existe procedimento dialético sem condutas éticas que caracterizem seus participantes. Pois, sendo o dialético aquele que tem condições de conhecer as realidades inteligíveis, ele conhecerá as realidades verdadeiras as quais são também o paradigma ou as normas a governarem suas condutas.
} 


\section{2 - O tema e o método}

As controvérsias sobre qual é verdadeiramente o tema do Filebo são variadas e antigas. Por exemplo, é difícil afirmar se 0 argumento central gira em torno do bem, da definição do que seria uma vida feliz para todos os homens, do Bem como princípio ontológico, ou ainda da manifestação das duas dimensões ao mesmo tempo, isto é, ôntica-ontológica. Parece tratarse de um bem para todos os homens, presentes e futuros. Entretanto, ao ser examinada a questão do Bem, conjuntamente com aquela da natureza do prazer e seus nexos com a reflexão e atividades cognitivas, a memória, o desejo e outras variáveis, se constata um nível de elaboração que ultrapassa o plano de uma enquête meramente empírica.

0 diálogo tem início quando Sócrates propõe o confronto entre o prazer, hedonê, e a reflexão, noûs, pela manifestação do bem, ou a felicidade humana, na medida em que participam de um único gênero, o Bem. Porém, segundo a inspiração socrática, a vida boa não é constituída nem só de prazer nem só de reflexão, mas de uma mistura dos dois. A categoria metafísica da mistura (meiktón), juntamente com o llimitado (ápeiron), o Limite (péras) e a Causa (aitía), compõe os quatro gêneros, uma forma de enquadramento platônico para tudo que existe no universo. Os quatro princípios ou causas constituem-se na forma de abordagem das coisas sensíveis seguindo a noção de "participação" (méthexis), novo aspecto da Teoria das Idéias, nos diálogos da última fase, da qual o Filebo, o Sofista, o Político e o Timeu fazem parte. Nesse sentido, o intelecto (noûs), a sabedoria (phrónesis), as diversas ciências (epistémai) e os prazeres (hedonaí) fazem parte da vida feliz, segundo a idéia de participação nas características formais do Uno e do Múltiplo, do Limite e do Ilimitado. Com a noção de "participação", que poderá envolver a relação entre as Idéias e as coisas sensíveis, entre gênero e espécie, Platão pretende melhor definir e justificar as Formas. Nesse sentido, essa concepção visa superar as dificuldades da relação entre as coisas sensíveis e as Idéias, como uma correspondência simétrica. Assim, se as coisas sensíveis, apesar de sua constante transformação, apresentam características distintivas, é porque elas recebem, de uma certa maneira, alguma coisa das Formas inteligíveis ${ }^{6}$. Com a relação de participação é permitido dizer, de uma certa maneira, que, por exemplo, "o belo é isso que torna belas todas as coisas belas" (Phédon 100d), ou elas são belas porque participam da Idéia de Belo.

${ }^{6}$ Com relação às Formas em Platão, ver: J.-F. Pradeau, (ed.), Platon: les formes intelligibles. Sur la forme intelligible et la participation dans les dialogues platoniciens, Paris, PUF, 2001. Como se sabe, a fundamentação que os diálogos consagram às realidades inteligíveis, às suas Formas e à sua natureza, bem como à relação de participação são breves, alusivas e peremptórias. Assim, é preciso deter-se nos textos dos diálogos, às suas lacunas e alusões, para tentar compreender o que são as realidades ou formas inteligíveis ou, ainda, as modalidades da participação, mesmo os resultados sendo incertos. 
0 modo de Platão enunciar os problemas a serem desenvolvidos no Filebo está diretamente relacionado com o método utilizado na sua investigação, isto é, o modelo literário do texto se articula com a ambição filosófica, de apreender, a partir de uma investigação formal, as articulações da natureza empírica. Assim, a formalização do problema coincide com a formalização do método de investigá-lo. Por isso, a compreensão da questão somente em termos lógicos, por exemplo, não-dialéticos, prejudica seu entendimento como um todo articulado. Sócrates, ao enunciar as duas teses, a de Filebo, dizendo ser o prazer o que há de melhor para todos os seres viventes e a sua de ser a reflexão, a sabedoria e tudo que lhe é aparentado, 0 melhor para todos os que podem dela participar, aponta uma diferença entre os dois lógoi apresentados. 0 ponto de partida está na constatação de que essa diferença diz respeito à variedade tanto dos prazeres como das formas de reflexão, ou seja, tanto um como outro, apesar da unidade nominal, são múltiplos. É apresentado, portanto, o problema da unidade e da multiplicidade, questão, aliás, que perpassa toda a filosofia platônica.

Para examinar a unidade e a multiplicidade, é necessário, como afirma Sócrates, superar a abordagem de nível elementar da aporia Uno-Múltiplo, pois é muito fácil contestar quem defende qualquer uma dessas posições, pueris e de fácil refutação. Prodigioso é quando alguém avança em suas afirmações e constata que "o Uno é múltiplo e indeterminado e que 0 múltiplo é Uno" (14e). Nessa afirmação, Platão intercala um termo novo para articular o Uno-Múltiplo. Trata-se do ápeíron. Ele esclarece que essa estrutura metafísico-numérica da realidade feita por meio da conexão UnoMúltiplo se estabelece através do raciocínio, circula em toda parte e é eterna. Esse presente divino aos homens nos foi transmitido pelos antigos que viviam mais próximo dos deuses do que nós ( $15 \mathrm{~d}-\mathrm{e})$. Conclui-se, então, que a identidade entre o Uno e o Múltiplo manifesta-se no pensamento, no raciocínio e circula, agora e sempre, em toda fala (linguagem). Para Platão, esse "fato permanente" e que nunca deixará de existir, é uma característica inerente e imortal dos nossos discursos que escapa ao envelhecimento (15e). Conseqüentemente, é nos argumentos do discurso onde se encontram todas as dificuldades de lidar com o problema da relação Uno-Múltiplo, mas é nele também que está o caminho para a solução. Além do mais, como Sócrates afirma (16c-d), a existência dos entes determinada pelo Uno e pelo Múltiplo implica, por natureza, a presença do Ilimitado, ápeíron e péras, Limite.

Toda essa articulação aponta para uma primeira dificuldade da ontologia platônica, no que se refere à teoria do conhecimento, visto que o existente e o verdadeiro não são claramente estabelecidos. Na determinação de como se dá o processo do conhecimento em relação à realidade, Platão o define como a relação de uma faculdade de conhecer em relação a um objeto verdadeiro e real e mesmo em relação a um objeto necessariamente real, eterno e indestrutível. Platão parece falar da verdade e da falsidade presentes nos julgamentos, como se ele tratasse das propriedades das coisas sobre as quais tratam esses julgamentos. No Sofista ficou estabelecido não 
ser possível conceber um enunciado sobre nada, pois todo lógos deve conter alguma coisa (263c). Entretanto, essa "alguma coisa" que se sabe não ser empírica, Platão a concebe como sendo um inteligível completamente real. Só o conhecimento inteligível, que tem como modelo a reminiscência, 0 qual não é ordenado a partir de informações sensíveis, permite atingir as Formas. Tendo tudo isso como pressuposto, o Filebo é um dos diálogos em que Platão apresenta uma possibilidade para conhecer o conjunto ordenado das Formas, além de apresentar o método filosófico mais adequado para tal. É a dialética concebida como o método filosófico mais apropriado para conhecer o mundo inteligível.

Aquele que se ocupa com a dialética deve saber reconhecer as semelhanças e as incompatibilidades existentes entre as várias Formas. 0 método de dividir e unificar, arte do discurso para abordar problemas, vem definido como o mais belo caminho (kallíon hodós 16b4). Entretanto, como Sócrates mesmo tem consciência, ele é fácil de indicar, mas muito difícil de praticar, pois ele não pode restringir-se à abordagem elementar do Uno-Múltiplo. Nesse sentido, Platão, evocando a sabedoria dos antigos, para dar um ar de verdade à sua afirmação, propõe, de acordo com M. Dixsaut, o seguinte estatuto para o ápeiron:

“a) Oposição à unidade, isto é, pluralidade ilimitada e unidade são os dois extremos da operação dialética (17a, 18a, 18e-19a); b) ele pode predicar uma unidade $(14 \mathrm{e})$ como também uma multiplicidade $(16 \mathrm{~d}) ; \mathrm{c}$ ) ele está ligado às coisas do devir. A participação é pensada como a presença (imanente ou transcendente) de uma unidade (uma mônada) nas coisas que são do devir e são indefinidas' (15b5)"7.

Com tal proposta para o llimitado, o filósofo mostra as dificuldades do discurso em dar conta da indeterminação à qual está submetida, mesmo uma multiplicidade nomeada. Por isso, Sócrates diz a Protarco: "a multiplicidade ilimitada das coisas individuais e a ilimitada multiplicidade que cada uma delas contém, te impedem, em cada caso, de pensá-las (17e6-9)".

\section{3 - A dialética como método}

Para Platão, no Parmênides, a dialética é a própria filosofia. No Sofista ele introduz o exemplo da caça para expor os procedimentos da diaíresis, mostrando diversas formas de divisão e tipos de sofistas. A diaíresis é um instrumento a serviço da dialética e não uma finalidade em si. Por isso, ela implica uma técnica a serviço do processo argumentativo, mas também

7 M. Dixsaut, 1999, p. XIII. 
uma ética para escolher entre o melhor e o pior. No Filebo, o processo dialético, a ética e a técnica, estão totalmente integrados, isto é, o método abarca 0 investigador e o tema investigado. 0 processo da diaíresis se refere a números, embora não se possa dizer que o método diairético possua uma natureza matemática. Nesse sentido, a diaíresis não é uma simples divisão. Ela é divisão a serviço de uma síntese. A exposição do método que Sócrates declara sempre ter sido amante, embora este o tenha deixado muitas vezes sem recurso e na aporia (16d), começa por um ponto recorrente em Platão: procurar em cada coisa existente uma idéia imanente a uma multiplicidade (16d). Após, quando se tiver apreendido a idéia existente em cada coisa, deve-se proceder a um exame atento, pois é certo que serão descobertas duas, três ou mais, idéias definidas, nela incluídas. A seguir, devese tomar cada uma dessas novas idéias e procurar um número (arithmós) limite de idéias compreendidas nelas e constituir essa operação, tanto quanto for necessário, para encontrar novas idéias. Somente quando não for mais possível repetir a operação é que "se pode deixar a unidade de cada coisa perder-se em liberdade no infinito" (16el-2). Com esse procedimento, que é 0 único digno de um verdadeiro dialético, será descoberto não somente que cada idéia é, ao mesmo tempo, una e infinitamente múltipla (hen kà polà kaì apeirá 16d6), mas também que multiplicidade ela encerra (hopósa).

A existência dos entes determinada pelo Uno e pelo Múltiplo implica, por natureza, a presença do Limite, péras, e do Ilimitado, ápeiron. Nesse contexto, tal afirmação tem como razão fundamental definir a especificidade do procedimento dialético em relação ao herístico no tratar o Uno-Múltiplo e o Indeterminado. Nos passos do processo dialético, recomenda Sócrates, a idéia de llimitado não deve ser atribuída à multiplicidade, antes de se ter percebido todos os números que estão nela contidos, desde o indeterminado até à unidade. 0 que Platão visa, segundo $M$. Dixsaut, é que

"o dialético deve colocar um número preciso de intermediários (este número dependerá do tipo de unidade que se visa dividir em sua multiplicidade, e do ponto de vista sobre o qual essa unidade é abordada), ele não deve passar imediatamente do um ao ilimitado, portanto deve tomar cuidado no dividir?

É por essa razão que Sócrates afirma:

"Os sábios de nosso tempo fazem o Uno e o Múltiplo mais depressa ou mais devagar do que deviam e passam logo da unidade ao indeterminado; os números intermediários escapam-Ihes e é isso que distingue a dialética da herística nas discussões que travamos uns com os outros" (17a5).

Portanto, o número de idéias presente numa Idéia deve ser sempre determinado e é essa determinação que visa o processo dialético. Com a dialética é possível nomear quais e quantas são as idéias contidas numa multiplicidade ilimitada de seres, de indivíduos.

8 M. Dixsaut, 1999, p. XV. 
Platão apresenta o processo dialético como um presente dos deuses aos homens, para que possam pesquisar, ensinar e instruir-se mutuamente uns aos outros. Ele critica seus contemporâneos que abordam a questão do Uno e do Múltiplo de forma inadequada e, assim, dão saltos indevidos da unidade para 0 indeterminado, perdendo os números intermediários. 0 procedimento minucioso e numericamente completo distingue a verdadeira dialética da herística nos debates filosóficos, isto é, ele afirma que existem duas vias, mas só uma é revelada pelos deuses. Deve-se compreender então, que existem duas vias e não duas maneiras de percorrer o mesmo caminho. A diferença não está na rapidez ou lentidão da passagem. Ela não se dá devido a um procedimento precipitado e um prudente, ou seja, não é à mesma unidade que se chega conforme se passe ou não pelos intermediários. Dessas duas maneiras de conceber o múltiplo, a dialética é mais louvável, pois, através dela as diferenças são feitas em uma progressão dimensionada do Múltiplo ao Uno. Não é possível passar de uma Idéia geral ou unidade à multiplicidade, indeterminada dos indivíduos empíricos, pois só se alcança filosoficamente a multiplicidade, após estabelecer as condições lógico-ontológicas da Idéia nas várias idéias.

A insistência no número e na natureza de cada coisa, além da ordem dos procedimentos em relação à Unidade e ao Indeterminado, indica o rigor necessário na aplicação do método dialético ao processo filosófico, porque ele visa examinar como o prazer, a reflexão e a sabedoria, cada um, pode ser, ao mesmo tempo, Uno e Múltiplo e, como podem, não sendo imediatamente indeterminados, realizar, ambos, um determinado número, antes de alcançar o Indeterminado.

\begin{abstract}
“A posição de um número determinado de intermediários é, pois, a estrutura intermediária pela qual deve necessariamente passar todo movimento dialético. Ou melhor, que se vá num sentido ou noutro - do um em direção ao ilimitado ou do ilimitado em direção ao um -, a unidade só será uma unidade determinada, portanto uma unidade real, se ele envolver uma multiplicidade precisamente constituída. Ir imediatamente do ilimitado à unidade é, de fato, ir do ilimitado ao ilimitado. Só a circularidade do um e do múltiplo pode fazer sair da indeterminação: o um só é esse um se ele é a unidade dessa multiplicidade, e uma multiplicidade para ser multiplicidade, deve, ao mesmo tempo, ser uma multiplicidade de unidades, e estar compreendida em uma unidade" ${ }^{\text {. }}$.
\end{abstract}

\title{
4 - A dialética e os gêneros
}

Seguindo os passos do método, como indica Sócrates, o problema que se apresenta para aquele que se ocupa com a dialética é tomar em mãos o Ilimitado. Num trabalho semelhante ao do deus Teuth, inventor do alfabe-

9 M. Dixsaut, 1999, p. XVII. 
to (18b-d), a tarefa consiste em organizar, a partir de uma realidade ilimitada, os elementos interdependentes entre si em um conjunto ordenado. Se o prazer e a reflexão são uma realidade encoberta em uma multiplicidade indeterminada, é preciso, para atingir a unidade do real, constituir uma multiplicidade nomeada. 0 que Sócrates pretende é constituir uma pluralidade ordenada dos dois elementos para substituir a inicial indeterminação. 0 exemplo de Teuth, portanto, vem ilustrar como deve ser conduzida a reflexão, quando se está diante do Ilimitado. Como constituir uma pluralidade nomeada, a partir de um Ilimitado não-determinado?

0 papel da dialética, enquanto téchnê, é o de ordenar a diversidade das coisas sensíveis em gênero e espécie. Isto é, com a finalidade de fazer um uso adequado da coisa em questão (o prazer e a reflexão), Platão visa o ser permanente de cada uma delas, para que cada singularidade seja reconhecida em sua inalterável identidade, de forma que possa, com a mesma certeza, ser verificada a possibilidade que existe de ela ser ou não associada a outras coisas. 0 que decorre dessa teoria geral da dialética é a distinção entre as diferentes espécies de prazer, bem como de todas as espécies de reflexão, dado que o ser mesmo de cada uma delas, ou sua inalterável identidade, deve ser examinado também em relação com outras coisas, a fim de, sob um ponto de vista ontológico, verificar sua potencialidade à medida. Quer dizer, se a vida feliz como manifestação do Bem é definida como uma mistura de prazer e reflexão, é a capacidade mútua de cada um em combinar-se numa justa proporção que dará condições de desvendar esse bem da existência humana.

Com uma linguagem fortemente pitagórica ${ }^{10}$, Platão argumenta que, baseado na ação do Limite sobre o Ilimitado, pode-se compreender a natureza Uno-M últiplo do real. As duas apresentações têm caráter diverso uma da

\footnotetext{
${ }^{10}$ Esta posição é um pouco controversa, pois, segundo alguns autores, não é em Pitágoras propriamente que Platão se apóia para construir sua teoria. É mais provável que tenha sido em Filolaus de Crotona, pois como para Aristóteles ele é a principal fonte do pitagorismo do século $V$ é bem possível que Platão, no Filebo, também faça referência ao seu sistema. A maneira como Filolaus formula sua tese nos leva a crer que ele responde à primeira geração de pensadores que sucedeu a Parmênides como Anaxágoras e Zenão, reconhecidos como filósofos da natureza. O fragmento 1 de Filolaus, hoje considerado como autêntico, coloca o Limite e o Ilimitado num mesmo plano, propondo-os como dois princípios paralelos, em vez de dar prioridade ao Ilimitado. Ele diz: "Ce sont les ilimités et les limitants qui ont, en s'harmonisant, constitué au sein du monde la nature, ainsi que la totalité du monde et tout ce qu'il contient." (Trad. Daniel Delattre, em Les Présocratiques, Pléiade, Paris, 1988). Assim, todas as coisas do mundo são, portanto, produto de uma continuidade inesgotável, de onde provém a contínua mudança e as estruturas perfeitas e acabadas que nelas se produzem. O Cosmos não é e nem nunca foi um caos, visto que o limite é tão original quanto o Ilimitado. Tal é a tradição de origem divina que Sócrates recebeu de seus ancestrais. Ver mais detalhes no artigo de Carl Huffman "Limite et Ilimité chez les premiers philosophes grecs", M. Dixsaut, 1999, v. II.
} 
outra, pois, enquanto a relação Uno-Múltiplo é um modelo metodológico, a relação Ilimitado-Limite pretende dar conta de um quadro metafísico mais abrangente. Assim, das análises do texto se constata que as duas ordenações não estão dispostas num mesmo plano, isto é, a relação UnoMúltiplo é dependente da relação Ilimitado-Limite. Além do mais, a identidade dos dois termos, a qual possibilita que um mesmo objeto possa ser descrito adequadamente, tanto em termos referentes à unidade quanto referentes à multiplicidade, exclui a possibilidade de o Uno e o Múltiplo serem assumidos como componentes isolados de cada objeto: cada coisa é um misto que mostra na unidade a marca de sua participação na Idéia de Limite e na multiplicidade a marca de sua participação na Idéia de Ilimitado.

0 entrelaçamento desses dois sistemas vem anunciado num segundo momento, quando a abordagem metafísica é apresentada, primeiramente, como a ação do péras sobre o ápeiron que dá origem a um misto, e segundo quando a Causa, externa a esse processo, fornece a causa eficiente ao mesmo. 0 real é um misto Uno-Múltiplo, que se apresenta como a determinação do indeterminado. Isso confirma a necessidade de eliminar toda tradicional interpretação da Idéia platônica como correspondência simétri$\mathrm{ca}$, no sentido de modelo e sua variante. 0 que vale é a ação de um termo sobre o outro e da Causa que torna possível essa ação. 0 sistema que emerge é baseado na capacidade própria do Limite de determinar uma multiplicidade, antes uma totalidade desordenada, sem negar o Múltiplo, mas antes organizando esse Múltiplo.

Quanto à força que determina o processo e à razão que lhe confere ordem, 0 Limite não age em virtude de si mesmo, mas em virtude de um poder externo. Com isso temos uma estrutura implicando diversos níveis de unificação, com uma relação que tem um duplo andamento: o processo descendente de explicitação em direção ao concreto e ao empírico e o processo ascendente de determinação, uma vez que só no todo as partes e as espécies têm sentido.

Do que foi apresentado decorre uma questão bastante controvertida entre aqueles que estudam o Filebo: que tipo de existência atribuir a essas unidades. Filósofos como Gadamer, Taylor, Guthrie, Hackforth, Migliori apresentam interpretações interessantes para esse argumento platônico ${ }^{11}$. Preferimos, por uma certa afinidade, a que Casertano $0^{12}$ apresenta por ser bastante coerente: "Ilimitado, Uno, Múltiplo, Limite são Idéias, e aqui uma Idéia é composta de outra Idéia que, no entanto, não é sua espécie, mas Ihe constitui a estrutura". Assim, "Limite e Ilimitado são a estrutura interna de cada Idéia, mas isso não significa que sirvam só para individuar o número limitado de espécie em que essa se divide: estrutura interna significa precisamente a possibilidade de pensar e nomear cada idéia singular".

11 Ver S. M. MACIEL, 2002, p. 61s.

12 G. Casertano, 1989, p. 96-98. 
Para que não haja equívoco, é importante distinguir os dois sentidos de estrutura: aquele no qual uma Idéia é colocada e aquele na qual é estruturada. Por exemplo, a Idéia de mamífero é estruturalmente inserida na Idéia de animal vertebrado; posteriormente mamífero é também estruturado em outras subespécies.

Assim, enquanto a primeira é o que possibilita pensar a Idéia em questão e nada é revelado sobre sua estrutura íntima, a segunda é a sua real manifestação e articulação, mas não influi, de fato, sobre sua pensabilidade. Além disso, há um Limite para cada nível, mas que é determinado por um nível superior: num momento é a Idéia de mamífero, mas ela é já determinada a partir da Idéia de vertebrado. Não há dúvida de que os dois processos são entrelaçados: enquanto determinada em um certo nível, exatamente porque é aquele gênero específico, aquela Idéia se subdivide em posteriores espécies em si determinadas, que resultam condicionadas à espécie dominante. Contudo, isso em nada altera o fato de que, para Platão, "a pensabilidade de uma Idéia é dependente da estrutura superior na qual é posta. É esta que determina a natureza acentuadamente vertical de seu sistema"13.

Platão mostra caminhos, mas isso não significa a inexistência de obstáculos para a solução do problema das teses opostas, hedonê, noûs e phrónesis, como bens do homem. Logo que são constituídas as suas unidades, por intermédio do método dialético, suas diferenças são, então, construídas a partir da unidade, e cada uma delas representa a possibilidade de uma multiplicidade de espécies. 0 método de divisão permite assim, a partir da unidade inteligível, captar as divisões formais que correspondem aos existenciais sensíveis. A construção dos intermediários em direção ao sensível não significa, necessariamente, que uma realidade seja atribuída aos objetos ou coisas sensíveis, pois estas são somente condições inteligíveis desses objetos e divisões objetivas do real. A ambição filosófica presente por trás desses procedimentos é sempre a de apreender, por meio de uma argumentação formal, as articulações empíricas da natureza. A definição da dialética é, portanto, freqüentemente ligada à apresentação da estrutura inteligível do real e à capacidade do julgamento verdadeiro de refletir sobre essa estrutura.

\section{Bibliografia}

CASERTANO, G. Il nome della cosa: linguaggio e realtà negli ultimi dialogui di Platone. Napoli, Loffredo Editore, 1998.

. Filosofare dialektikos in Platone: il Filebo, Elenchos 10 (1989) 61-102.

13 M. MIGLIORI, 1998, p. 149. 
DAM ACIUS. Lectures on the Philebus. Amsterdam, L.G. Westerink, 1959.

DIXSAUT, M. (ed.). La fêlure du plaisir: études sur le Philèbe de Platon, v. I e II. Paris, Vrin, 1999. Vrin, 2001.

. Métamorphoses de la dialectique dans les dialogues de Platon. Paris,

FREDE, D. (ed.). Plato, Philebus. Indianapolis/Cambridge, Hackett Publishing Company, 1993.

GOLDSCHMIDT, V. Les Dialogues de Platon. Structure et méthode dialectique. Paris, PUF, 1982.

HAM PTON, C. Pleasure, Knowledge, and Being. An Analysis of Plato's Philebus. Albany, State University of New York Press, 1990.

JAMBLIQUE. Protreptique. (Ed. et trad. E. des Places). Paris, PUF, 1989.

JOLY, R. Le thème philosophique des genres de vie dans l'Antiquité classique. Bruxelles, Peeters, 1995.

MACIEL, S. M. Ética e felicidade: um estudo do Filebo de Platão. Porto Alegre, EDIPUCRS, 2002.

MIGLIORI, M. L'uomo fra piacere, intelligenza e Bene. Commentario storicofilosofico al Filebo di Platone. Milano, Vita e Pensiero, ${ }^{2} 1998$.

PLATON. Philèbe. In DIĖS, A. (ed.). Paris, Les Belles Lettres, 1949.

PRADEAU, J. F. (ed.). Platon les Formes intelligibles. Paris, PUF, 2001.

SPERBER, M. (ed.). Philosophie Grecque. (Avec la collaboration de Jonathan Barnes, Luc Brisson, Jacques Brunschwig, Gregory Vlastos). Paris, PUF, 1998.

Endereço da Autora:

La Fontaine Haute

82120 Mansonville - France

e-mail: sonyamaciel@yahoo.fr 